\title{
Susuk: Charm needles in orofacial soft tissues ${ }^{*}$
}

\author{
Sathesh Balasundram ${ }^{1 \#}$, Sherrie Chong Mei Yee $^{2}$, P. Shanmuhasuntharam ${ }^{2}$ \\ ${ }^{1}$ Department of Oral and Maxillofacial Surgery, Hospital Sultanah Nora Ismail Batu Pahat, Johor, Malaysia \\ ${ }^{2}$ Department of Oral and Maxillofacial Surgery, University of Malaya, Kuala Lumpur, Malaysia \\ Email: " satbala@yahoo.com
}

Received 4 April 2013; revised 25 April 2013; accepted 8 May 2013

Copyright (C) 2013 Sathesh Balasundram et al. This is an open access article distributed under the Creative Commons Attribution License, which permits unrestricted use, distribution, and reproduction in any medium, provided the original work is properly cited.

\begin{abstract}
Purpose of the Study: To understand the reasons for charm needle insertions, chemical constituents of charm needles and their significance to magnetic resonance imaging. Materials and Methods: Confidential interviews were used to collect information from charm needle wearers. Two attempts at surgical removal of charm needles were carried out. Charm needle samples were chemically analyzed using EPMA method. A review of literature on the possible complications of charm needles in relation to MRI was made. Results: Patients had varied reasons for wearing charm needles including to be physically attractive, to overcome personal problems and for protection. Charm needles were made of gold alloy consisting of gold $(85.2 \%-88.6 \%)$, copper $(9.3 \%-10.8 \%)$ and trace elements of aluminium and silver. As such, MRI may not be a hazard to charm needle wearers given the fact that gold is non-ferromagnetic. However, artefacts may potentially distort the MR imaging. Conclusion: A tactful manner in handling these patients may be to ignore the needles unless a clinical need warrants intervention. The surgical removal of these needles may be a straightforward procedure, but the localization is usually a challenging task. At present, the pertinent literature does not contain carefully controlled studies that demonstrate the absolute safety of charm needle exposure to powerful magnetic fields.
\end{abstract}

Keywords: Susuk; Charm Needles; Talisman; Foreign Body

\section{INTRODUCTION}

Charm needles or susuk as they are colloquially called

*Financial Disclosure: None.

Conflict of interest statement: None.

${ }^{\#}$ Corresponding author. are metal-based pin-like bodies, commonly inserted within the soft tissue. These needle-like talismans are usually inserted beneath the skin of various parts of the human body, including the orofacial region, chest, back, pubic area and lower limbs.

The insertion of "susuk" is a common practice in Southeast Asia, especially in Malaysia. While it is more common with Malays, some Chinese and Indians are also known to have resorted to this ritual of inserting foreign objects under the skin for various purposes. These include enhancing youth, charm, charisma, and confidence. This practice is also believed to render protection against injury and accidents.Gold needles are the most popular, and their implant is known as charm needles. These embedded needles are not visible to the naked eye, and the number of needles may vary.

Charm needles are almost always an incidental finding in radiographs. The most common orofacial region with such insertion included the forehead, cheeks, lips or over the mandible [1]. Usually placed via extraoral approach, these needles have been found to be superficially inserted beneath the skin.

The mystical practice of charm needles insertion has not abated in recent years. More and more dental practitioners have become aware of such "foreign bodies" both in Asian and Western countries. Immigration and travel have not confined these strange findings in a specific geographic location [2]. Oon (1973) [3] corresponded noting that this practice is quite wide-spread in Singapore.

These radiological oddities can sometimes pose challenging diagnostic problems for clinicians as they occasionally resemble root filling or amalgam pins. Awareness of its existence is important to avoid misdiagnosis and mismanagement of these patients and to enhance patient management and to prevent embarrassment to the patients [2,4].

There has been some misconception on the possible risks associated with the charm needles and magnetic resonance imaging (MRI) among dental practitioners and 
surgeons. The potential hazard of these needles to the patients undergoing MRI scans has not been addressed adequately.

The aim of our study is to describe a case series of susuk wearers and to comprehend the rationale for susuk insertions. We also aim to identify the metal constituents of susuk and to review the literature on possible complications in relation to magnetic resonance imaging.

\section{MATERIALS AND METHODS}

We interviewed seven patients who were susuk wearers pertaining to this practice. Two of these patients requested for removal of these charm needles and surgery was attempted.

\subsection{Patients Wearing Susuks}

We liaised with the Dental Radiology Unit, Faculty of Dentistry, University of Malaya in identifying patients who had susuk showing up in their radiographs. These patients were interviewed in the Department of Oral and Maxillofacial Surgery.

\subsection{Chemical Analysis of Susuk}

Three needles were sent to the Department of Geology, University of Malaya for chemical analysis using the EPMA (Electron Probe Micro Analysis) method using Cameca ${ }^{\circledR}$ SX 100 Electron Probe Micro Analyzer. A portion of each susuk sample was obtained and prepared on grain mounts before being placed into the Electron Probe Micro Analyzer's sample stage for analysis.

\section{RESULTS}

We interviewed seven patients, every individual with a different background and personal belief.

\subsection{Case Series}

\subsubsection{Case 1}

A 35-year-old Indian male security guard was referred to the Department of Oral and Maxillofacial Surgery for the management of a laceration injury due to dog bite. The occipitomental radiograph (Figure 1) revealed two radiopaque objects resembling fine needles in the frontal and symphyseal regions. Clinically, neither of the needles was palpable.

The patient had the susuk inserted by a Hindu priest as a protective charm. A custom-made gold needle was purchased in a local goldsmith shop. The needle was approximately $5 \mathrm{~mm}$ in length and $0.5 \mathrm{~mm}$ in diameter. The item cost him two Malaysian Ringgit (MYR 2) or approximately USD 0.67 .

The location of insertion (left buccomental region) was determined by the priest, the reason was not made

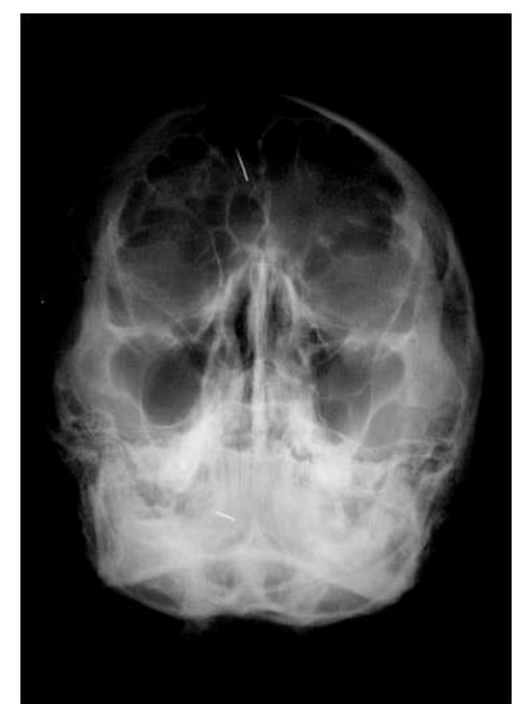

Figure 1. Occipitomental view of Case 1 showing charm needles in the right parasymphyseal region and the right frontal region.

known. One month after the event, the patient had another charm needle inserted in the right eyebrow region. The patient was reassured that there was no contraindication associated wearing of these needles in his face, neither were there any prohibitions. Confidentiality was not a necessity.

\subsubsection{Case 2}

A 64-year-old Chinese housewife was referred to the Department of Oral and Maxillofacial Surgery for the management of submasseteric abscess. Routine dental panaromic radiograph (OPG) (Figure 2) revealed the presence of a radiopaque needle-like object in the mandibular region.

Following treatment, the patient was asked concerning the "foreign body". She denied any knowledge about this and claimed to not have had any needles inserted. She denied having any past history of maxillofacial trauma. The patient expressed preference not to have any more discussion pertaining to the susuk.

\subsubsection{Case 3}

A 59-year-old Chinese retired businesswoman sought prosthetic treatment. Clinical examination revealed a horizontally placed palpable needle The OPG (Figure 3 ) of this patient showed a charm needle located at the right body of the mandible, distal to the lower left canine.

Following her case review, the patient was further interviewed regarding the needle-like "foreign body". This patient had sought for a charm needle with the hope that it would make her more likeable to her acquaintances.

No particular reason was given for the location of the insertion. The needle which was obtained by the bomoh 


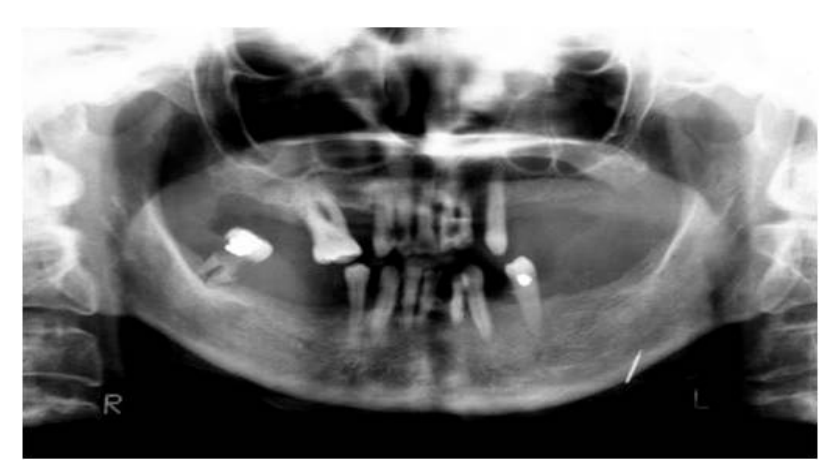

Figure 2. OPG of Case 2 revealing one needle at the left lower border of the body of the mandible.

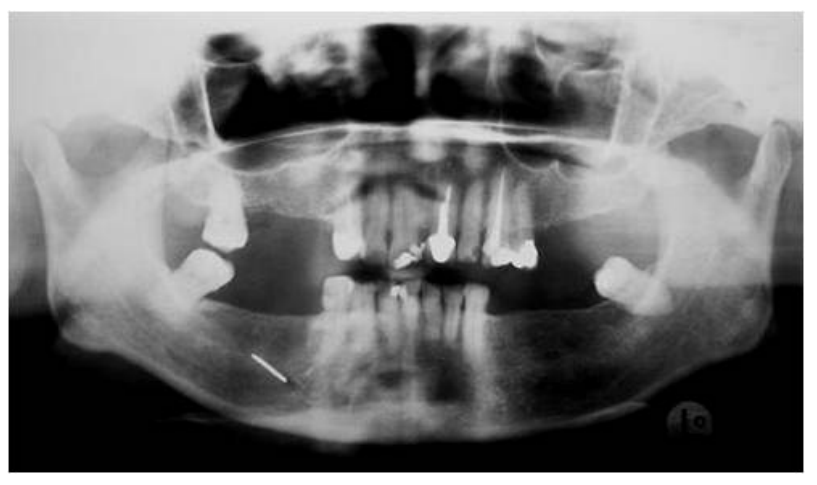

Figure 3. OPG of Case 3 showing one needle superimposed at the right body of the mandible, distal to the left canine.

himself was placed through the skin causing a piercinglike sensation. The ritual took about three minutes. She was charged MYR 10 (USD 3.36) by the bomoh for the whole "treatment".

Asked about contraindications associated with the wearing of the needle, she could not recall any. She was prohibited from consuming drumstick (Moringa oleifera) known locally as murunggai in Tamil language and buah kelo in Malay language. She could not recall whether confidentiality was a necessity.

The patient requested for the removal of the needle. A minor surgery to remove the needle was successfully carried out.

\subsubsection{Case 4}

A 35-year-old Malay woman who works in a factory, a congenital cleft palate patient, had sought treatment in Faculty of Dentistry, University of Malaya. Upon her OPG assessment, three radiopaque needle-like objects in the orofacial region were noticed (Figure 4) in the maxillary and symphyseal regions.

Initially denying the presence of any needles in her orofacial tissue, she finally disclosed that in search of a male companion, she sought the insertion of susuk to enhance her attractiveness.

Prior to the insertion of susuks, the patient purchased

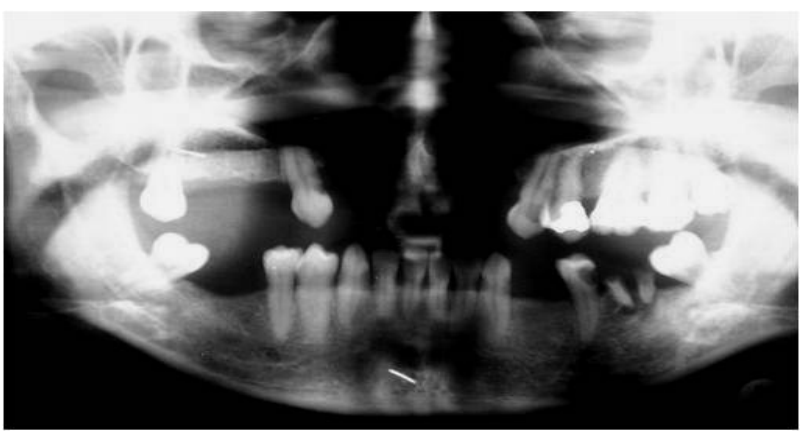

Figure 4. OPG of patient in Case 4 revealing three needles. However, only two are visible here, one at the symphyseal region, the other superimposed on the roots of 18 . The susuk on the left maxillary region could not be reproduced in the image above as it overlaps a radiopaque restoration.

the needles at a local goldsmith shop, priced at MYR 3 (USD 1) each. The needles were custom-made by the goldsmith for the purpose. The ritual took approximately two hours, which included some oil rubbing, chanting and pushing the needles into the skin.

The patient was prohibited from consuming a type of banana namely lady finger bananas (Musa acuminata colla.), drumstick and satay from the stick (small pieces of marinated meat skewered on an 8-inch bamboo stick and grilled over open flame). There was no necessity to keep the presence of the needles confidential. However, she preferred to be secretive about them to avoid embarrassment.

Upon request for removal of these needles, an appointment was given for surgical removal of the needles. However, the patient subsequently declined the surgery as there was no potential clinical risk to the patient.

\subsubsection{Case 5}

A 67-year-old edentulous Malay housewife sought dental care to have a new pair of dentures made. Routine radiographic examination revealed five radiopaque, needlelike objects scattered around the mandibular region (Figure 5). Clinical palpation did not suggest the presence of any needles.

Initially a little embarrassed, the patient later disclosed that she decided to have susuk inserted to prevent the infidelity of her husband.

The gold needles were obtained by the bomoh. The charm needles were inserted after a brief period of chanting. No sensation was felt when the needles were inserted. She was charged MYR 10 (USD 3.36) per needle. No contraindications for the wearing of the charm needles were mentioned. Prohibitions included avoiding food such as papaya (Carica papaya), lady finger bananas and drumstick. She preferred to be secretive about the incident to avoid embarrassment though it was not a necessity. 


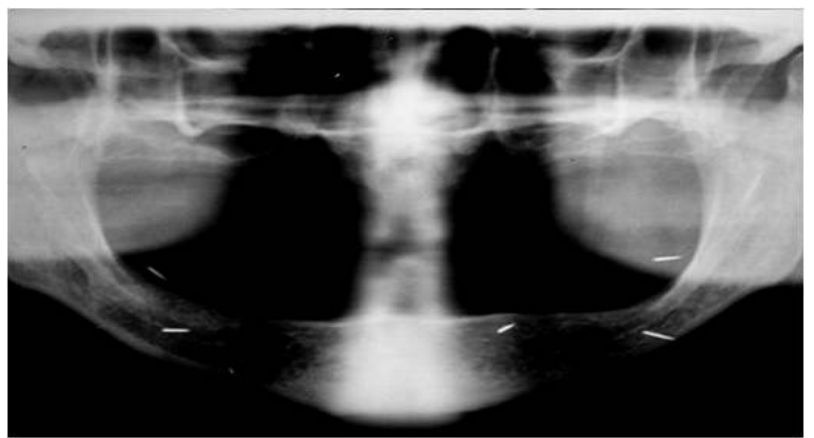

Figure 5. OPG of Case 5 clearly showing five needles scattered at the mandibular region.

Further appointment was given to make her a new pair of prosthesis.

\subsubsection{Case 6}

A 36-year-old self-employed Chinese man who was under periodontal care underwent routine OPG investigation (Figure 6) which revealed the presence of two radiopaque needle-like objects in the maxillary region. Clinically, the needles were not palpable.

During the interview, the patient disclosed that the needles were inserted as a protective charm from evil spirits. The gold needles (also known as "Tungkapan" in Thai language) were obtained from a goldsmith shop for MYR 45 (USD 15.12) each. The patient's spiritual master placed the needles in his palms as he chanted. It could have been that the patient went into a trance or was hypnotized as he stated the insertion of the needles was not discernable to the patient. The site of insertion was believed to prevent negative energy from entering the patient via his skull. The ritual took about 15 minutes.

No prohibition was mentioned and confidentiality pertaining to the needles was not necessary. This patient requested for the needles to be removed and a surgical removal attempt was carried out.

\subsubsection{Case 7}

A 60-year-old Eurasian housewife sought dental extraction in the Department of Oral and Maxillofacial Surgery. A periapical radiograph (Figure 7) taken prior treatment revealed a radiopaque needle-like object at the left side near the roots of the first molar tooth. Clinically, the needle was not palpable.

The patient was further questioned regarding the needle-like objects. She denied participating in any such mystical rituals; neither did her parents tell her of having any such "foreign bodies" inserted within her facial tissue in her younger days.

The patient first became aware of the presence of such needle-like objects in 1973, after having a radiograph taken of the head. She perceived that an ex-colleague had possibly mystically inserted these charm needles within

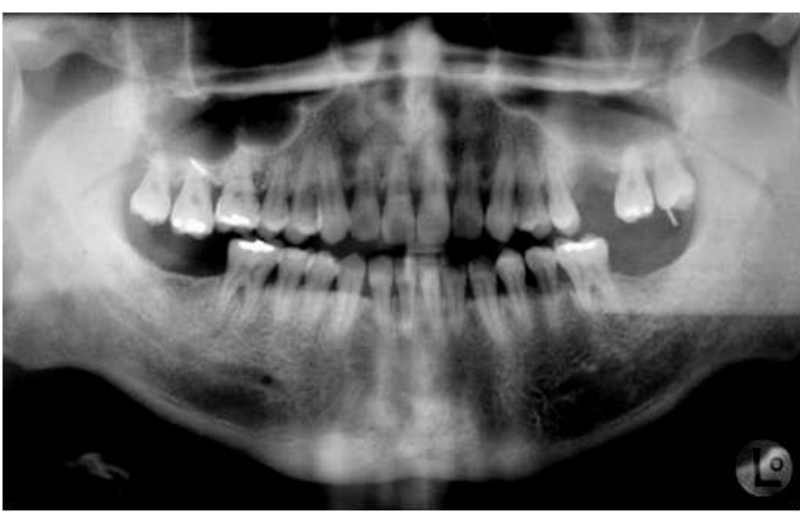

Figure 6. OPG of patient in Case 6 showing two susuk superimposed on the upper molars, one at the apex of 17 and the other on the crown of 28 .

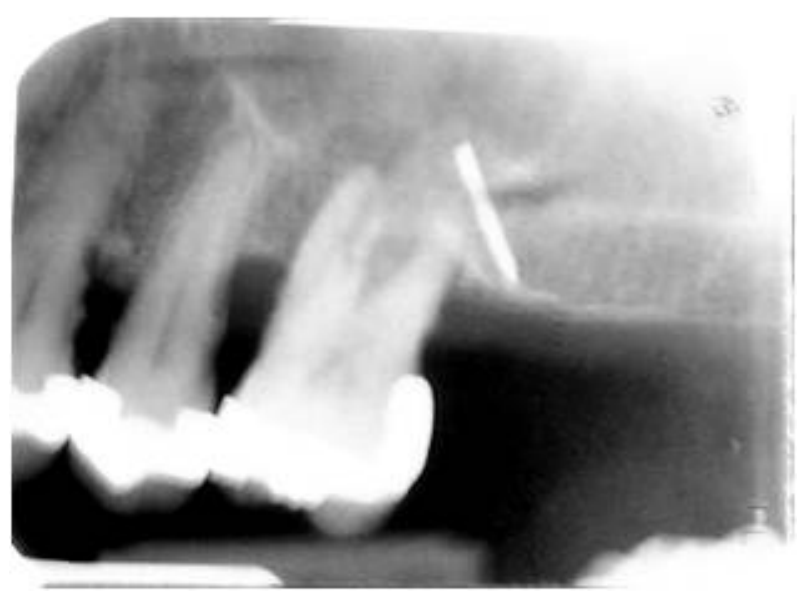

Figure 7. Periapical radiograph taken of patient in Case 7 of the upper left posterior region showing one needle near the apex of 26.

her soft tissues out of personal rivalry. She claimed not to have any knowledge as to how the needles were inserted. A Roman Catholic who believed in witchcraft, the patient had since visited many bomoh to have these needles removed, but to no avail.

The patient believed that these "charm needles" could have been the likely cause of her asthma, sinusitis, migraine and ophthalmic problems. She also claimed to occasional paraesthesia in the affected site.

The patient was discharged after an uncomplicated dental extraction.

\subsection{Surgical Removal of Charm Needles}

\subsubsection{Patient 1}

A 59-year-old Chinese woman (patient in Case 3) requested for the removal of a charm needle located within the soft tissue in the right body of the mandible. The surrounding tissue was healthy. As the needle was clinically palpable, an extra oral localizing mark was made along the location of the needle (Figure 8). A small extra oral 


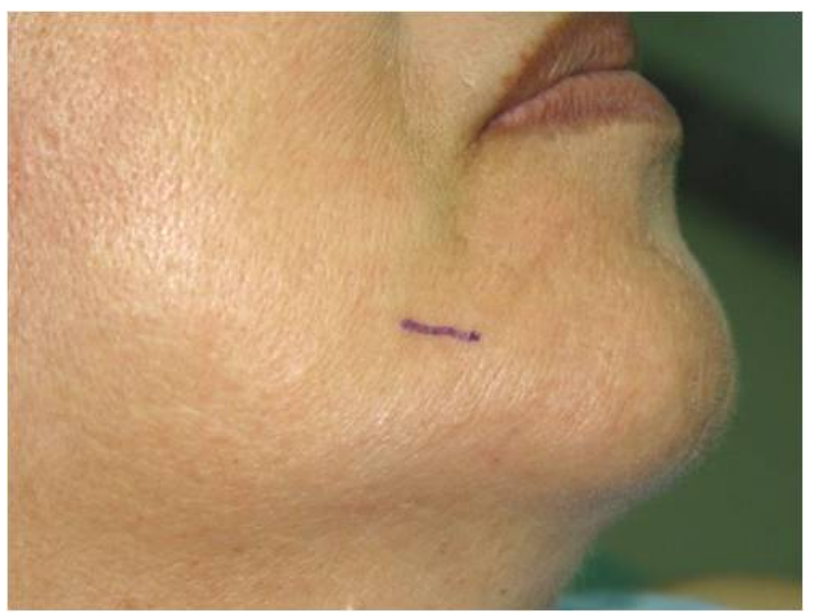

Figure 8. Extraoral localizing mark made along the location of the needle.

incision, approximately $5 \mathrm{~mm}$ in length was made near the blunt end of the needle (Figure 9). An artery forcep was inserted to attain a grip of the needle. Despite being able to grip the needle, some manupulation was needed to remove the needle as it seemed to be encased in a fibrous capsule (Figure 10). The needle was $1.5 \mathrm{~cm}$ in length and $1 \mathrm{~mm}$ in diameter (Figure 11).

No post-operative complications were noted.

\subsubsection{Patient 2}

Ultrasound imaging was performed to locate the needles in the soft tissues. Before the scan was done, an anterior posterior skull radiograph was taken to help orientate the position of the needles relative to the other anatomical structures of the orofacial skeleton. The ultrasound imaging to detect the needles was disrupted due to echoreflection and images of white striations that resembled reflective figures of metal made the localization of charm needles in the soft tissue a difficult task.

The minor surgery carried out on the left side via an extra oral approach. Attempt was then made to locate the needle using a dental probe (probe 9) and an artery forceps. However failure to locate the needle after exploring deeper forced the surgeon to abandon the procedure under local anaesthesia. No attempt was made to explore deeper due to the risk of damaging the branches of the facial nerve.

An intra oral approach to removal the needles under general anaesthesia was offered to the patient, but was declined. Upon review, the healing was uneventful.

\subsection{Chemical Analysis of Susuk Samples}

Three samples were sent for chemical analysis to find out their constituents using the EPMA method as mentioned, namely Sample A, Sample B and Sample C. Sample A was bought by the authors from a goldsmith shop, Sam-

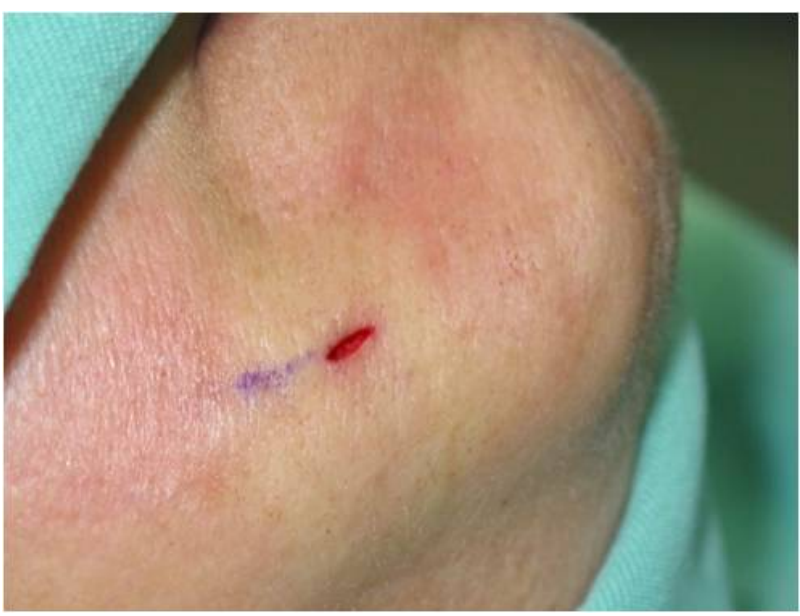

Figure 9. Incision made on the skin.

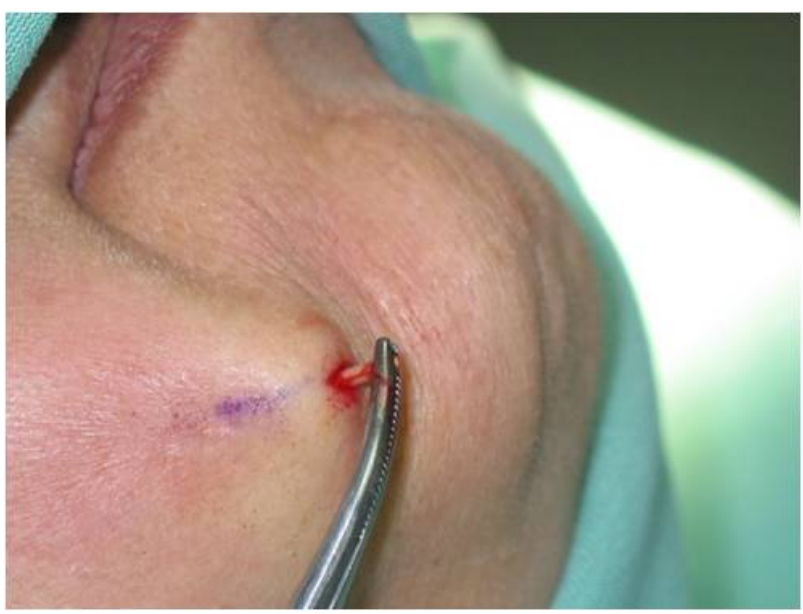

Figure 10. Removal of susuk. Note the puckering skin indicating that the susuk may be encased in a fibrous capsule.

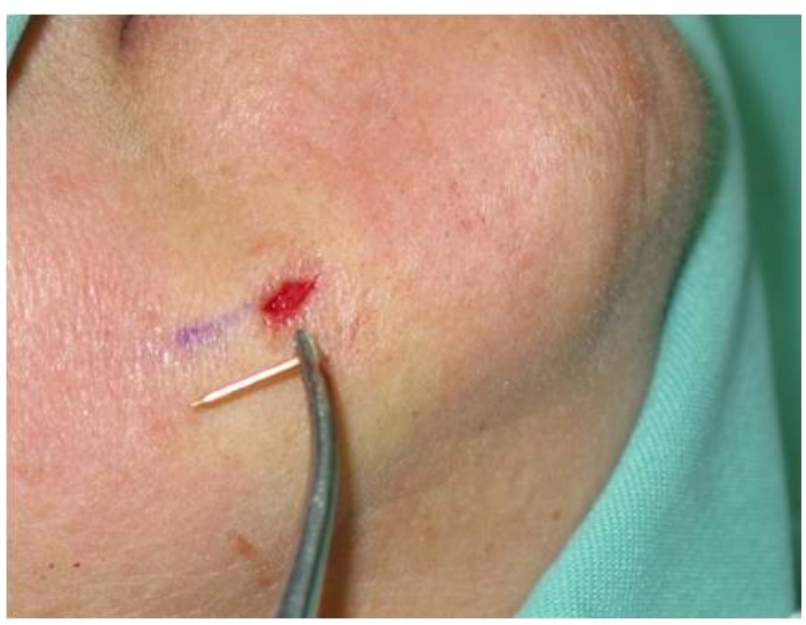

Figure 11. The removed susuk.

ple B and Sample C were susuks removed from patients. The results are as in Table $\mathbf{1}$.

The susuks consisted mostly of gold $(\mathrm{Au})$, copper $(\mathrm{Cu})$ 
Table 1. Results of EPMA on susuk samples.

\begin{tabular}{cccc}
\hline \multirow{2}{*}{ Element } & \multicolumn{3}{c}{ Norm Concentration Weight \% } \\
\cline { 2 - 4 } & Sample A & Sample B & Sample C \\
\hline $\mathrm{Au}$ & 85.1748 & 86.0200 & 88.6456 \\
$\mathrm{Ag}$ & 4.2437 & 2.9703 & 2.0191 \\
$\mathrm{Cu}$ & 10.5056 & 10.8453 & 9.2910 \\
$\mathrm{Al}$ & 0.0097 & 0.0048 & 0.0122 \\
$\mathrm{Fe}$ & 0.0324 & 0.0332 & 0.0097 \\
$\mathrm{Si}$ & 0.0338 & 0.1264 & 0.0224 \\
Total & 100.0000 & 100.0000 & 100.0000 \\
\hline
\end{tabular}

and silver (Ag). Gold made up the bulk of the content of the needles at more than $85 \%$ of the norm concentration weight percentage in each samples. Other trace elements present were aluminium ( $\mathrm{Al})$, iron $(\mathrm{Fe})$ and silicon (Si).

\subsection{Magnetic Resonance Imaging (MRI)}

Magnetic resonance imaging (MRI) has become increasingly important as an imaging technique in cross-sectional imaging of head and neck diseases. Examination with the MRI is based on the properties of protons in a strong magnetic field. MRI is a non-invasive method of examination which does not use ionizing radiation or radioactive preparation. On the other hand, in the immediate surroundings of the MR scanner, there is a strong constant attraction exerted on ferromagnetic materials [5]. Thus, a concern of possible injury to the patient arises if the charm needle is displaced or dislodged. Schrom et al. (2006) [6] reported that eyelid implants made of pure gold did not carry any risk of heating or dislocation.

However, when the literature implies that an implant or device is MR safe, the thoroughness and competence of the investigation must be assessed as well as considering whether the results are applicable to another MR system, sequence, and situation. Importantly, it should be noted that many of the ex vivo tests performed to date determine MR safety for biomedical implants, materials, and devices using MR systems with static magnetic fields of $1.5 \mathrm{~T}$ or lower. Nambiar et al. (2008) reported on suspending a susuk inside a 1.5-T MRI machine to determine if it was attracted by the machine's magnet and found that susuk showed no ferromagnetic characteristics [7]. Nevertheless, it is conceivable that an object that exhibits "nonferromagnetism" or weak ferromagnetic quailties in association with a 1.5-T MR system may be attracted with sufficient force to pose a hazard to an individual in an MR environment that has a magnet operating at 2.0-T or higher and this must be acknowledged as many centers move to the higher field systems now available [8]. At present, the pertinent literature does not contain carefully controlled studies that demonstrate the absolute safety of charm needle exposure to powerful magnetic fields.

Another aspect of introducing metallic objects into the MR system is image distortion. The distortion of MR images by various materials is caused by disruption of the local homogenous magnetic field resulting in a change in the position frequency relationship, which is crucial for accurate image reconstruction. Image distortion can occur and it is the responsibility of the staff involved to ensure that artefact does not result in an incorrect diagnosis [8].

\section{DISCUSSION}

This study revealed that the insertion of charm needles is not an uncommon practice among all ethnic groups in Malaysia. Indeed, the practice among all races bears a lot of similarity in terms of the purposes for their insertions. The scientific background of such practice is yet to be established. Thus, no clinical benefits could be verified.

Placement of charm needles will traditionally be done during a special ritual which may include chanting and rubbing of oil over the site before the needles are inserted through the skin into orofacial soft tissues-as in our group of patients. The wearers are usually advised to follow some strict prohibitions. However, these prohibitions do not apply to all wearers, but depend on the beliefs of the bomoh or priests. Confidentiality was usually requested by the susuk wearers to prevent embarrassment because they believed that such practices were socially condemned.

Surgical removal of these needles is usually straightforward, although localizing them can be a challenging task. This may warrant additional investigations which do not necessarily result in a precise localizing of the needles.

The results from the chemical analysis of the susuk samples confirmed the results from previous reports that charm needles are indeed made up of gold alloy. This explains their inert character in soft tissues. Loh and Ling (1992) [9], reported that the average gold content in their study was $89.75 \%$ and that the average copper content was $10.25 \%$. Our analysis of susuks had less than $90.0 \%$ of gold and consisted of copper and silver as well. Aluminium (Al), Iron (Fe), and Silicon (Si) were also present in traces. We perceive that gold has been used due to its biocompatibility to human tissue. Copper was essential to enable the needle to be shaped accordingly and increasing its hardness. The trace elements were likely to be contamination during handling or manufacturing of the needles. Despite usually being made out of gold, Chao (1997) [10], reported charm needles which were corroded and broken down due to muscle movement over a period of time. No further investigations were reported pertaining to the constituents of the charm needles. Nev- 
ertheless, the breaking down of these needles does not negate the possible risk of dislodgement of the needle particles into vital structures.

From an oral surgery perspective, Loh and Yeo (1989) [11], have described a patient presenting soft tissue infection related to the vicinity of the charm needles. Despite gold being an inert material, the non sterile methods of inserting these needles introduce possible contaminants into the soft tissues. This also possibly elucidates the recurrent inflammations at the site of insertions. The high vascularity in the orofacial region may contain the inflammation, resulting in a fibrous capsule surrounding the susuks. This is evident in our Case 3 patient and Loh and Yeo's (1989) [11] patient where the needles were encased in fibrous capsules.

Charm needles may be mistaken for foreign bodies introduced during an accident, acupuncture needles, or wrongly diagnosed as root fillings or retention pins in dental X-rays. The needles do not cause pain or swelling and are not visible externally. They should be left alone unless they lead to infection or interfere with surgical procedures or radiotherapy on the face and neck [12].

It is also interesting to note that apart from one patient (Case 7) in this series, none of the patients had any clinical symptoms associated with the needles. Lim et al. (2005), who reported a similar clinical scenario, ruled out that such symptoms were related to the charm needles [13]. It is yet to be ascertained if the clinical symptom of paraesthesia in our patient was directly related to the needles or merely a coincidence.

It is not uncommon to find more than one susuk in a patient. However, when a single charm needle over a particular location of jaws is present, clinicians who are not familiar with the existence of such talisman may be confused by this foreign body, and unnecessarily investigative procedures and treatment may be prescribed [11].

Chao (1997) highlighted an interesting point from the forensic point of view of such patients [10]. If a patient claims to have been pricked or assaulted with a needle, further imaging of other parts of the body may be useful to determine if there are similar needles inserted. Such needles could be charm needles and therefore would probably not be associated with the assault.

\section{CONCLUSION}

A tactful manner in handling these patients may be to ignore the needles unless a clinical need warrants intervention. The surgical removal of these needles may be a straightforward procedure but the localization is usually a challenging task. It is important to retain a sense of perspective. Although there have been at least $10 \mathrm{MR}$ related deaths, one blinding, over 200 incidents of patient burns, and $100 \mathrm{~s}$ of ferromagnetic missile incidents perhaps as many as 100 million MR investigations have been conducted without adverse effects. Although many MRI safety investigations have been carried out at up to $1.5 \mathrm{~T}$, the reader will be reminded that as many centers install magnets of $2.0 \mathrm{~T}$ and above, much of the current safety literature [14-19] cannot be simply extrapolated to these higher field strengths and further investigations will be required to reassure staff and patients of the limits of their safe use.

\section{CONSENT}

Informed consent was obtained from the patients for publication of this case series and any accompanying images.

\section{REFERENCES}

[1] Shanmuhasuntharam, P. and Ghani, S.H.A. (1991) Susuks: Charm needles in facial soft tissues. British Dental Journal, 170, 309-311. doi:10.1038/sj.bdj.4807525

[2] Layton, S. (1991) Letters: Susuks, charm needles in facial soft tissues. British Dental Journal, 170, 40. doi:10.1038/sj.bdj.4807568

[3] Oon, C.L (1973) Correspondence, “Charm needles”. Medical Journal of Malaysia, 27, 231-232.

[4] Stankiewics, N. (2000) Letters to the editors, Susuks. Dentomaxillofacial Radiology, 29, 254-255.

[5] de Keizer, R.J. and te Strake, L. (1986) Intraocular lens implants (pseudophakoi) and steelwire sutures: A contraindication for MRI? Documenta Ophthalmologica, 61, 281-284. doi:10.1007/BF00142354

[6] Schrom, T., Thelen, A., Asbach, P. and Bauknecht, H.C. (2006) Effect of 7.0 Tesla MRI on upper eyelid implants. Ophthalmic Plastic \& Reconstructive Surgery, 22, 480482. doi:10.1097/01.iop.0000240807.42320.d9

[7] Nambiar, P., Ibrahim, N., Tandjung, Y.R.M. and Shanmuhasuntharam, P. (2008) Susuks (charm needles) in the craniofacial region. Oral Radiology, 24, 10-15. doi:10.1007/s11282-008-0069-3

[8] Dempsey, M.F., Condon, B. and Hadley, D.M. (2002) MRI safety review. Seminars in Ultrasound, CT, and MRI, 23, 392-401. doi:10.1016/S0887-2171(02)90010-7

[9] Loh, F.C. and Ling, S.Y. (1992) Analysis of the metallic composition of orofacial talismans. Oral Surgery, Oral Medicine, Oral Pathology, 73, 281-282. doi:10.1016/0030-4220(92)90121-6

[10] Chao, T.C. (1997) Beware of charm needles! Journal of Clinical Forensic Medicine, 4, 33-35. doi:10.1016/S1353-1131(97)90006-7

[11] Loh, F.C. and Yeo, J.F. (1989) Talisman in the orofacial region. Oral Surgery, Oral Medicine, Oral Pathology, 68, 252-255. doi:10.1016/0030-4220(89)90204-1

[12] Teo, S.K. (2006) A woman with hidden charm needles. The Journal of the Royal College of Physicians of Edinburgh, 36, 211-212.

[13] Lim, E.C., Ng, T.H. and Seet, R.C. (2005) A woman 
whose radiographs showed subcutaneous metallic objects. Canadian Medical Association Journal, 19, 150.

[14] Donovan, J.J., Goldstein, J.I., Newbury, D.E., Echlin, P., Joy, D.C., Fiori, C. and Lifshin, E. (1992) Scanning electron microscopy and X-ray microsanalysis. 2nd Edition, Electron Probe Microanalysis, Plenum, New York.

[15] Shellock, F.G. and Crues, J.V. (2004) MR procedures, biologic effects, safety, and patient care. Radiology, 232, 635-652. doi:10.1148/radiol.2323030830

[16] Shellock, F.G. and Spinazzi, A. (2008) MRI safety update 2008, part 1: MRI contrast agents and nephrogenic systemic fibrosis. American Journal of Roentgenology, 191, 1129-1139. doi:10.2214/AJR.08.1038.1

[17] Shellock, F.G. and Spinazzi, A. (2008) MRI safety update
2008, part 2: Screening patients for MRI. American Journal of Roentgenology, 191, 1140-1149.

doi:10.2214/AJR.08.1038.2

[18] Boutin, R.D., Briggs, J.E. and Williamson, M.R. (1994) Injuries associated with MR imaging, survey of safety records and methods used to screen patients for metallic foreign bodiesbefore imaging. American Journal of Roentgenology, 162, 189-194. doi:10.2214/ajr.162.1.8273663

[19] Shellock, F.G. and Crues 3rd, J.V. (2002) MR Safety and the American College of Radiology White Paper. American Journal of Roentgenology, 178, 1349-1352. doi:10.2214/ajr.178.6.1781349 